\title{
ADUBAČ̃̃O FOLIAR COM MACRO E MICRONUTRIENTES NO CRESCIMENTO DE MUDAS MICROPROPAGADAS DO ABACAXIZEIRO CV. GOLD [Ananas comosus (L.) Merrill] EM DIFERENTES RECIPIENTES ${ }^{1}$
}

\author{
Foliar fertilization with macro and micronutrients in the growth of plantlets micropropagated \\ of pineapple cv. Gold [Ananas comosus (L.) Merrill] in different containers
}

\author{
Izaias dos Santos Bregonci², Edilson Romais Schmildt ${ }^{3}$, Ruimário Inácio Coelho ${ }^{4}$, \\ Edvaldo Fialho dos Reis ${ }^{5}$, Vitor José Brum ${ }^{6}$, Juliano Gonçalves dos Santos ${ }^{7}$
}

\begin{abstract}
RESUMO
Objetivou-se com este trabalho avaliar o efeito da adubação foliar com macro e micronutrientes no crescimento das mudas micropropagadas do abacaxizeiro cv. Gold [Ananas comosus (L.) Merrill], em diferentes recipientes. O experimento foi em esquema fatorial 8x3, adubação foliar em 8 níveis e recipientes em 3 níveis, através de um delineamento inteiramente casualizado com 5 repetições. As mudas foram padronizadas com altura média de $7,12 \mathrm{~cm}$. As adubações foliares foram feitas com uréia, cloreto de potássio, ácido bórico, um formulado comercial com macro e micronutrientes e testemunha (pulverização com água) e os recipientes: bandeja de isopor com 200 células; tubete pequeno de $115 \mathrm{~cm}^{3}$; e tubete grande com $300 \mathrm{~cm}^{3}$. $\mathrm{O}$ substrato utilizado foi o plantmax hortaliças ${ }^{\circledR}$. Avaliaram-se as características área foliar, altura de planta e massa seca da parte aérea e da raiz, aos 140 dias do transplantio. Os adubos foliares proporcionaram maior crescimento em área foliar, altura e massa seca da parte aérea às mudas do abacaxizeiro, embora com resultados diferentes. Os adubos foliares não aumentaram a massa seca do sistema radicular. A bandeja de isopor apresentou as menores médias, com todos os adubos foliares para área foliar, altura e massa seca da parte aérea das mudas do abacaxizeiro. $\mathrm{O}$ tubete pequeno e o tubete grande apresentaram resultados semelhantes com a maioria dos adubos foliares utilizados.
\end{abstract}

Termos para indexação: Abacaxi, micropropagação, fertilização.

\section{ABSTRACT}

The objective of this work was to evaluate the effect of the foliar fertilization with macro and micronutrients on the growth of the plantlets micropropagated of pineapple cv. Gold [Ananas comosus (L.) Merrill] in different containers. The experiment was mounted in factorial arrangement $8 \times 3$, with foliar fertilization in 8 levels and containers in 3 levels, through a completely randomized design with five repetitions. The plantlets were standardized with average height of $7,12 \mathrm{~cm}$. The foliar fertilization was used in the urea, potassium chloride, boric acid, a commercial formulated with macro and micronutrients and witness (pulverization with water) and the containers were: polystyrene tray with 200 cells; small tubete with $115 \mathrm{~cm}^{3}$; and big tubete with $300 \mathrm{~cm}^{3}$. The substratum used for all the containers was the plantmax hortaliças ${ }^{\circledR}$. The foliar area characteristics, plant height and dry mass of the aerial part and of the root at 140 days after planting were evaluated. All the foliar fertilizers, in all used containers, provided larger growth in foliar area, height and dry mass of the aerial part to the plantlets of the pineapple, however with different results. The foliar fertilizers do not increase the dry mass of the radicular system. The container polystyrene tray presents the smallest averages for foliar area, height and dry mass of the aerial part of the plantlets of the pineapple with all the foliar fertilizer. The containers small tubete and big tubete present similar results in all levels of foliar fertilizers.

Index terms: Pineapple, micropropagation, fertilization.

(Recebido em 21 de maio de 2007 e aprovado em 13 de novembro de 2007)

\footnotetext{
${ }^{1}$ Parte da Dissertação do primeiro autor, apresentada ao Centro de Ciências Agrárias da Universidade Federal do Espírito Santo/PPGPV, Alegre-ES como parte das exigências para obtenção do grau de Mestre em Produção Vegetal/Fitotecnia.

Engenheiro Agrônomo, Mestre em Produção Vegetal - Instituto Capixaba de Pesquisa, Assistência Técnica e Extensão Rural/INCAPER - Avenida Olívio Correa Pedrosa, 556 - Centro - 29500-000 - Alegre, ES - izaias@incaper.es.gov.br

${ }^{3}$ Engenheiro Agrônomo, Doutor, Professor - Departamento de Ciências da Saúde, Biológicas e Agrárias - Centro Universitário Norte do Espírito Santol CEUNES - Rua Humberto de Almeida Francklin, 257 - Universitário - 29933-480 - São Mateus, ES - edilsonschmildt@ceunes.ufes.br

${ }^{4}$ Engenheiro Agrônomo, Doutor, Professor - Departamento de Produção Vegetal - Centro de Ciências Agrárias/CCA - Universidade Federal do Espírito Santo/UFES - Alto Universitário, s/n - Centro - Cx. P. 16 - 29500-000 - Alegre, ES - ruimario@cca.ufes.br

${ }^{5}$ Engenheiro Agrícola, Doutor, Professor - Departamento de Engenharia Rural - Centro de Ciências Agrárias/CCA - Universidade Federal do Espírito Santo/UFES - Alto Universitário, s/n - Centro - Cx. P. 16 - 29500-000 - Alegre, ES - edreis@cca.ufes.br

${ }^{6}$ Engenheiro Agrônomo, Mestre em Produção Vegetal - Departamento de Desenvolvimento Educacional/DDE - Br. $259, \mathrm{Km} 70$ - Zona Rural - Cx. P. 256 79709-910 - Colatina, ES - vitorbrum@eafcol.gov.br

Graduando em Agronomia - Departamento de Produção Vegetal - Centro de Ciências Agrárias/CCA - Universidade Federal do Espírito Santo/UFES Alto Universitário - Cx. P. 16 - 29500-000 - Alegre, ES - juliano_agronomia@hotmail.com
} 


\section{INTRODUÇÃO}

As mudas micropropagadas de abacaxizeiro, após sua retirada do meio de cultivo in vitro, são transplantadas para recipientes de pequenas dimensões e volumes, os quais proporcionam pequenos espaçamentos entre mudas e pequenas disponibilidades de nutrientes. Essas condições limitam o crescimento das mudas.

Para produção comercial de mudas micropropagadas, precisa-se aprimorar e/ou adequar técnicas de cultivos durante a fase de aclimatação, visando aumentar a eficiência e diminuir custos (SOUZA JÚNIOR et al., 2001). Entre essas necessidades de aprimoramento, citam-se: substratos, recipientes, nutrição e espaçamentos entre mudas.

Buscando condições ótimas para crescimento de mudas micropropagadas de abacaxizeiro na fase de préaclimatação em casa de vegetação, têm sido estudado diversos substratos (MOREIRA, 2001; MOREIRA et al., 2006; SILVA et al., 1998; SOUZA JÚNIOR et al., 2001); tipos de recipientes (SOUZA JÚNIOR et al., 2001); nutrição através da hidroponia (MARTINS et al., 2002), fertilização de substrato (MOREIRA, 2001); adubação foliar (SILVA et al., 1998) e adição de isolados de bactérias ao substrato e raízes (MELLO et al., 2002; WEBER et al., 2003).

A adubação foliar pode ser uma alternativa estratégica para proporcionar um crescimento mais rápido das mudas micropropagadas, abreviando o tempo de passagem dessas para a nova fase de aclimatação (viveiro no chão com cobertura de sombrite).

A arquitetura do abacaxizeiro e suas características morfológicas e anatômicas favorecem a absorção foliar de nutrientes. Normalmente, as adubações foliares têm sido utilizadas para fertilização suplementar do NK aplicados ao solo; aplicações em épocas de baixas precipitações hídricas; e para adubação com micronutrientes (SOUZA, 1999).

Adubação foliar em mudas de abacaxizeiro requer cuidados especiais, entre eles a concentração de adubos nas soluções, que não deve passar de 10,0\%; a uréia não deve ultrapassar $5,0 \%$, cloreto de potássio deve estar entre 1,0 e 3,0\%, o sulfato de zinco entre 0,5 e 2,5\% (SOUZA, 1999). Reinhardt (1998) e Reinhardt \& Cunha (1999) recomendam adubações foliares com uréia e sulfato de potássio em mudas de secções de caule com 6 a 8 semanas de plantadas, com altura de 4,0 a 5,0 cm. Siebeneichler et al. (2005) confirmaram a mobilidade do boro em plantas de abaxizeiro Pérola e, Picchioni et al. (1995), citado por Siebeneichler et al. (2002) citam que a absorção foliar do boro é rápida, comparável à da uréia. Coelho (2005) encontrou respostas positivas para aumento da altura, área foliar, massa fresca e seca das mudas de secções de caule do abacaxizeiro 'Smooth Cayenne' quando usou adubação foliar com NK e B.

Objetivou-se, neste trabalho avaliar o crescimento das mudas micropropagadas do abacaxizeiro cv. Gold, [Ananas comosus (L.) Merrill] na fase de pré-aclimatação em casa de vegetação, submetidas a diferentes níveis de adubo foliar e cultivado em diferentes recipientes.

\section{MATERIAL E MÉTODOS}

O trabalho foi conduzido em casa de vegetação, instalada no Campus do Centro de Ciências Agrárias da Universidade Federal do Espírito Santo - CCA-UFES, município de Alegre-ES, localizado geograficamente a $20^{\circ}$ 46' S e $41^{\circ} 33^{\prime} \mathrm{W}$, com altitude de $277 \mathrm{~m}$; temperatura média anual de $22,6{ }^{\circ} \mathrm{C}$; média das máximas de $29,1{ }^{\circ} \mathrm{C}$; média das mínimas de $17,9^{\circ} \mathrm{C}$; e precipitação anual média de $1.292 \mathrm{~mm}$.

A cultivar utilizada no experimento faz parte da coleção de genótipos de abacaxizeiros do INCAPER Instituto Capixaba de Pesquisa, Assistência Técnica e Extensão Rural do Espírito Santo e apresenta características agronômicas desejadas pelo mercado consumidor. As mudas micropropagadas foram produzidas e, aclimatizadas por 20 dias no Laboratório de Biotecnologia-BIOMUDAS - de Venda Nova do Imigrante-ES. Elas estavam em bandejas de isopor de 200 células com substrato plantmax ${ }^{\circledR}$, e foram transferidas para a casa de vegetação de pré-aclimatação do CCA-UFES, onde permaneceram até o dia da montagem do experimento, recebendo duas irrigações por microaspersão diariamente, com vazão de $140 \mathrm{~L} \mathrm{~h}^{-1} \mathrm{e}$ espaçamento entre microaspersores de 2,00 m por $1,00 \mathrm{~m}$. A irrigação estava programada para funcionar às 10:00 h e 18:00 h, com duração de 4 minutos cada. As mudas receberam, durante os primeiros 15 dias de pré-aclimatação, diurnamente, pulverizações com água de 3 em 3 horas.

A implantação do experimento foi no dia 15/04/2006, sendo as mudas padronizadas com altura média de 7,12 $\mathrm{cm}$, com desvio-padrão de $\pm 0,63 \mathrm{~cm}$. A irrigação foi mantida conforme estabelecido pela programação do sistema automatizado. A avaliação final do experimento foi feita aos 140 dias após o transplantio.

O experimento foi montado em esquema fatorial $8 \times 3$, sendo a adubação foliar (ADF) em 8 níveis e recipientes (RECI) em 3 níveis, através de um delineamento inteiramente casualizado, com 5 repetições.

Os adubos foliares foram utilizados nas seguintes dosagens por litro: $\mathrm{T} 1=2 \mathrm{~g}$ de uréia $+2 \mathrm{~g}$ de cloreto de potássio; $\mathrm{T} 2=5 \mathrm{~g}$ de uréia $+5 \mathrm{~g}$ de cloreto de potássio; $\mathrm{T} 3$ $=10 \mathrm{~g}$ de uréia $+10 \mathrm{~g}$ de cloreto de potássio; $\mathrm{T} 4=\mathrm{T} 1+0,5$ $\mathrm{g}$ de ácido bórico; T5 = T2 + 0,5 g de ácido bórico; T6 = T3 
+ 0,5 g de ácido bórico; T7 = 3,0 g de um formulado comercial com macro e micronutrientes; e Test $=$ Testemunha (pulverização com água) e os recipientes (Figura 1) foram: BI = bandeja de isopor com 200 células, formato piramidal invertido de base quadrada de $2,5 \mathrm{~cm}$ de lado, altura de $5,0 \mathrm{~cm}$ e volume de $24 \mathrm{~cm}^{3} ; \mathrm{TP}=$ tubete pequeno, com diâmetro de $3,5 \mathrm{~cm}$, altura de $14,0 \mathrm{~cm}$ e volume de $115 \mathrm{~cm}^{3}$ e TG = tubete grande, com diâmetro de $5,0 \mathrm{~cm}$, altura de $19,0 \mathrm{~cm}$ e volume de $300 \mathrm{~cm}^{3}$.

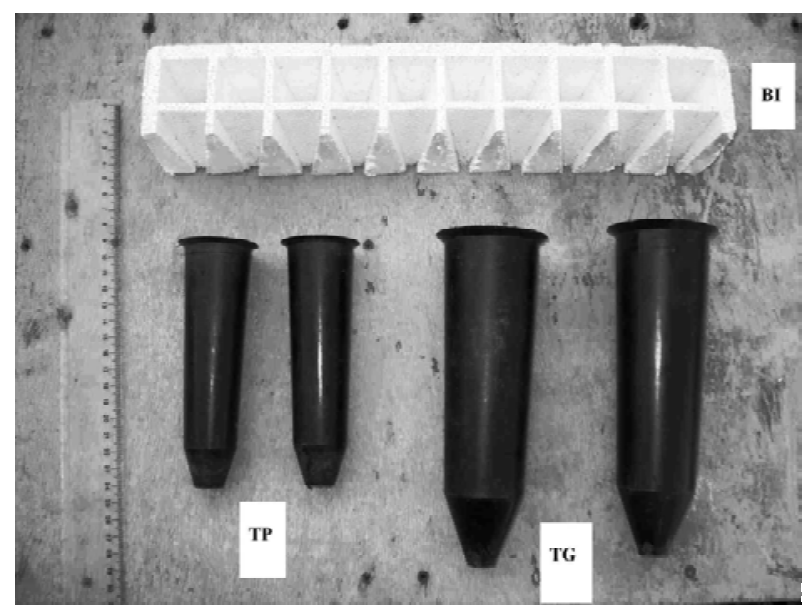

Figura 1 - Recipientes utilizados no cultivo de mudas micropropagadas do abacaxizeiro cv. Gold, bandeja de isopor (BI), tubete pequeno (TP) e tubete grande (TG).

$\mathrm{O}$ formulado comercial com macro e micronutrientes possuía a seguinte concentração de nutrientes: $15,0 \%$ de $\mathrm{N} ; 15,0 \%$ de $\mathrm{P}_{2} \mathrm{O}_{5} ; 20,0 \%$ de $\mathrm{K}_{2} 0 ; 1,1 \%$ de Ca; $4,0 \%$ de $\mathrm{S}$; $0,4 \%$ de $\mathrm{Mg} ; 0,05 \%$ de $\mathrm{Zn} ; 0,05 \%$ de $\mathrm{B} ; 0,1 \%$ de Fe, e $0,03 \%$ de Mn.

O boro foi aplicado, nos seus respectivos níveis, a partir da $1^{\mathrm{a}}$ pulverização, em semanas alternadas.

As adubações foliares eram sempre feitas no final da tarde, após as 17 horas.

As doses de uréia e $\mathrm{KCl}$ (NK), dos níveis dos adubos foliares, tiveram suas doses fornecidas progressivamente do seguinte modo: os tratamentos, com exceção da Test e $\mathrm{T} 7$, receberam nas 3 primeiras semanas a mesma dose, ou seja, $2 \mathrm{~g} \mathrm{~L}^{-1}$; a partir da $4^{\mathrm{a}}$ semana os tratamentos T2, T3, T5 e T6 passaram a receber $5 \mathrm{~g} \mathrm{~L}^{-1}$; e a partir da $8^{\mathrm{a}}$ semana T3 e T6 passaram a receber $10 \mathrm{~g} \mathrm{~L}^{-1}$.

O substrato utilizado para todos os recipientes foi o plantmax hortaliças ${ }^{\circledR}$. Em todos os recipientes fez-se uma disposição das mudas de forma a manter um espaçamento de aproximadamente $36,00 \mathrm{~cm}^{2}$ por muda e, cada muda representou uma parcela.
Avaliaram-se as características: área foliar (AFO), através do método das pesagens das folhas, conforme metodologia descrita por Benincasa (2003); altura de planta (ALT), medida com régua graduada em milímetros a partir do colo da planta até a extremidade da maior folha; massa seca da parte aérea (MSA) e da raiz (MSR), mensuradas através de balança analítica com precisão de 0,0001 g. Para determinação da massa seca, as amostras permaneceram em estufa de circulação forçada de ar por 72 horas, a $70^{\circ} \mathrm{C}$.

Os dados experimentais foram submetidos à análise de variância, e as médias foram comparadas pelo teste de Scott-Knott, para os níveis de adubo foliar, em estudo isolado ou sua interação e, pelo teste de Tukey para os níveis dos recipientes, em estudo isolado ou sua interação, sempre a $5 \%$ de probabilidade, utilizando o software SAEG 9.0.

\section{RESULTADOS E DISCUSSÃO}

A análise de variância do experimento (dados não apresentados neste trabalho) mostra interação significativa entre os fatores (ADF e RECI) para todas as características avaliadas, exceto para área foliar, onde os fatores são significativos isoladamente. Assim, observa-se na Figura 2(A), que todos os níveis de adubo foliar proporcionam acréscimos da área foliar, quando comparados a Test, com destaque para os níveis de adubos foliares T2, T4 e T6, que apresentam os maiores valores médios, não diferindo significativamente entre si, resultado que está de acordo com aqueles encontrados por Coelho (2005). Para essa mesma característica, os maiores valores médios para recipientes, em ordem decrescente são: TP, TG e BI (Figura 2(B)).

A altura das mudas observa-se pela Figura 3. O efeito dos níveis de adubação foliar dentro de cada nível de recipientes, mostra que todos os níveis de adubo foliar proporcionaram maiores alturas para as mudas, quando comparadas com a Test em todos os recipientes, concordando com resultados obtidos por Coelho (2005). Mas, há respostas diferentes entre os adubos foliares em cada recipiente. Assim, na BI, os melhores níveis de adubo foliar são o T2, o T3 e o T6. No TP, não há diferença significativa entre os adubos foliares, apenas desses para a Test. No TG os melhores resultados são proporcionados pelos níveis de adubo foliar T3, T5 e T6.

$\mathrm{O}$ efeito dos níveis de recipientes dentro de cada nível de adubo foliar, observa-se que a BI apresenta os menores valores em todos os níveis de adubos foliares, sendo que não há diferença significativa entre o TP e o TG, exceto na Test (pulverização com água). Igualmente, Souza Júnior et al. (2001) encontraram melhores resultados para altura de mudas micropropagadas de abacaxizeiro 'Pérola' com tubete pequeno $(5,0 \mathrm{~cm}$ de diâmetro $\mathrm{x} 13,0 \mathrm{~cm}$ de altura) e saco plástico $(10,0 \mathrm{~cm}$ x 8,0 cm). 
(A)

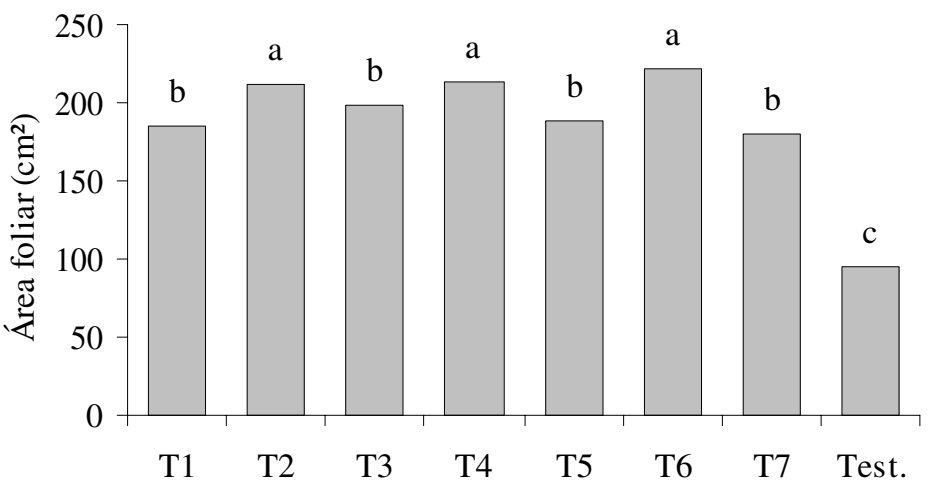

(B)

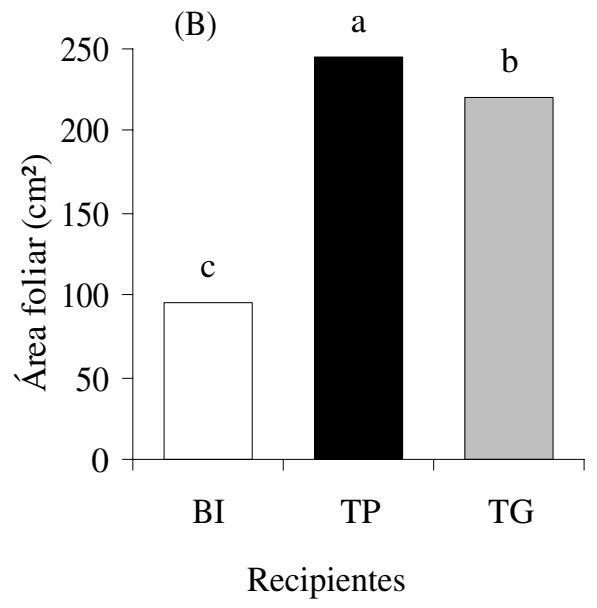

*Letras iguais para níveis de adubo foliar e para níveis de recipientes, não diferem significativamente entre si, respectivamente, pelo teste de Scott-Knott e Tukey, a 5\% de probabilidade.

Figura 2 - Área foliar das mudas micropropagadas do abacaxizeiro cv. Gold aos 140 dias após transplantio em função dos níveis de adubo foliar (A) e dos níveis de recipientes (B).

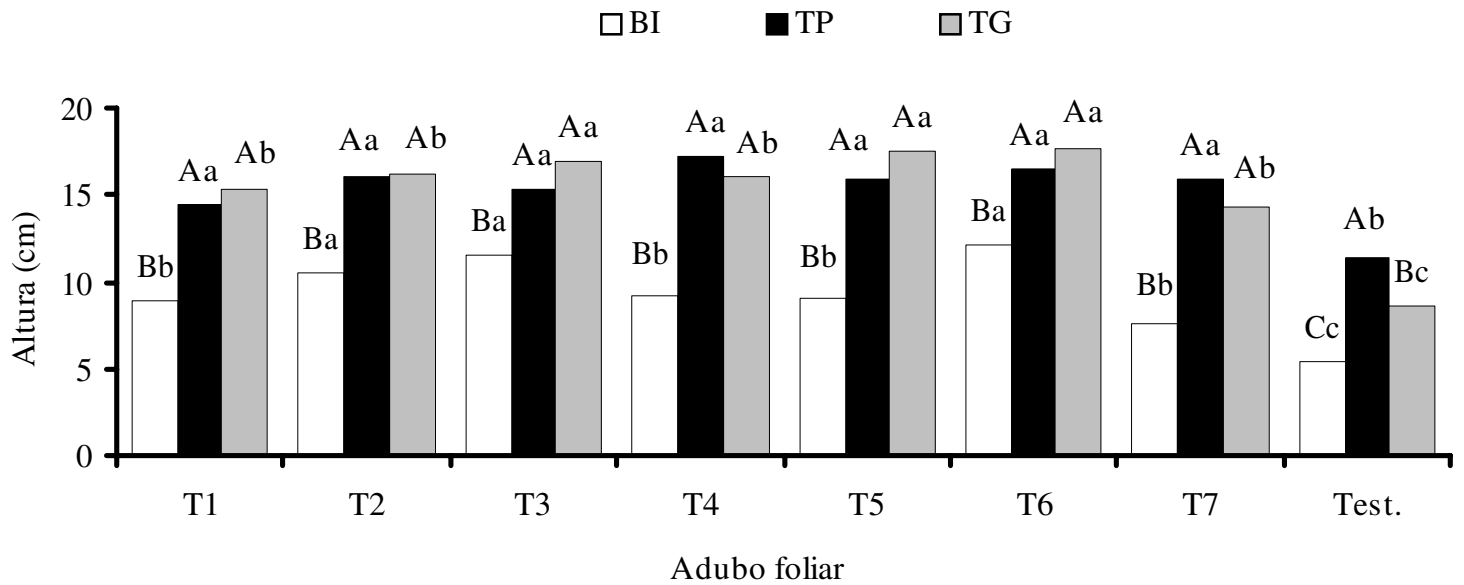

*Letras iguais, maiúsculas para recipientes dentro de cada nível de adubo foliar e minúsculas para adubo foliar dentro de cada nível de recipiente, não diferem significativamente entre si, respectivamente, pelo teste de Tukey e Scott-Knott, a 5\% de probabilidade.

Figura 3 - Altura das mudas micropropagadas do abacaxizeiro cv. Gold aos 140 dias após o transplantio para a interação entre níveis de adubo foliar e níveis de recipientes: bandeja de isopor (BI), tubete pequeno (TP) e tubete grande (TG).

A massa seca da parte aérea está representada na Figura 4. Evidencia-se que todos os adubos foliares proporcionam aumento da massa seca da parte aérea, quando comparados a Test, concordando com resultados obtidos por Coelho (2005) com a cultivar Smooth Cayenne, e Weber et al. (2003) para as cultivares Perolera $(1,845-$ 1,913 g) e Primavera (2,257-2,792 g), exceto os adubos T5 e T7 na BI e o adubo foliar T3 no TP.
A BI apresenta os menores valores médios em todos os níveis de adubo foliar, não havendo diferença significativa entre TP e TG em todos os níveis de adubo foliar, exceto no adubo $\mathrm{T} 7$ e na Test.

Visualiza-se na Figura 5 a massa seca da raiz. Na BI os maiores valores médios são para os níveis de adubo foliar T1, T2, T3 e T4, não diferindo significativamente entre si, enquanto que no TP e no TG os adubos foliares 


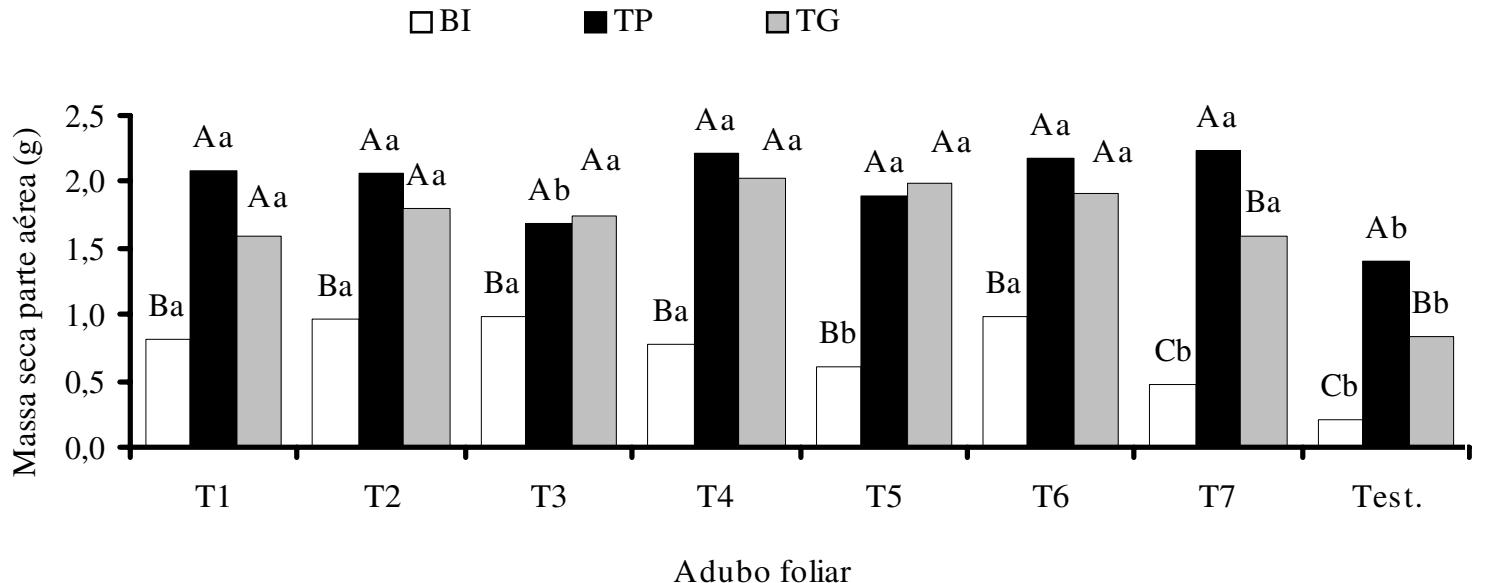

*Letras iguais, maiúsculas para recipientes dentro de cada nível de adubo foliar e minúsculas para adubo foliar dentro de cada nível de recipiente, não diferem significativamente entre si, respectivamente, pelo teste de Tukey e Scott-Knott, a 5\% de probabilidade.

Figura 4 - Massa seca da parte aérea das mudas micropropagadas do abacaxizeiro cv. Gold aos 140 dias após o transplantio para a interação entre níveis de adubo foliar e níveis de recipientes: bandeja de isopor (BI), tubete pequeno (TP) e tubete grande (TG).

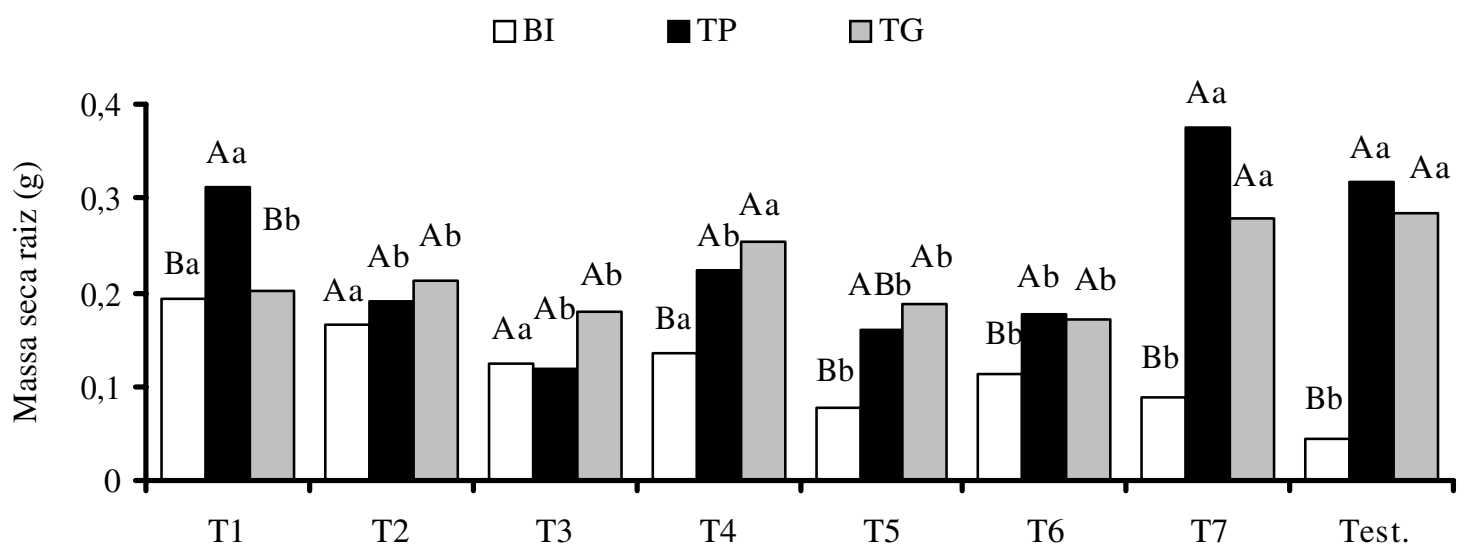

Adubo foliar

*Letras iguais, maiúsculas para recipientes dentro de cada nível de adubo foliar e minúsculas para adubo foliar dentro de cada nível de recipiente, não diferem significativamente entre si, respectivamente, pelo teste de Tukey e Scott-Knott, a 5\% de probabilidade.

Figura 5 - Massa seca da raiz das mudas micropropagadas do abacaxizeiro cv. Gold aos 140 dias após transplantio para a interação entre níveis de adubo foliar e níveis de recipientes: bandeja de isopor (BI), tubete pequeno (TP) e tubete grande (TG).

proporcionam menores valores médios, exceto o adubo foliar T7 e T1 no TP e o adubo foliar T7 e T4 no TG, que não diferem significativamente da Test, nos seus respectivos recipientes. Resultados semelhantes foram encontrados por Silva et al. (1998) que com dose superior a $1,0 \mathrm{~mL} \mathrm{~L}^{-1}$ do adubo foliar Kelpak ${ }^{\circledR}$ (macro e micronutrientes), combinado com Agromix ${ }^{\circledR}$, verificaram redução na massa fresca de raiz.
Observa-se que entre os adubos foliares T2 e T3 não há diferença significativa entre os recipientes utilizados. Também, não há diferença significativa entre os recipientes TP e TG nos adubos foliares T4, T5, T6, T7 e Test, havendo apenas deles, nestes mesmos níveis de adubo foliar, para BI, exceção no adubo foliar T5, que não apresenta diferença significativa entre TP e TG. Entretanto, 
TP é superior no adubo foliar T1 e, não há diferença entre TG e BI nesse adubo foliar. Resultados para massa seca da raiz, semelhantes aos verificados no TP e TG, foram encontrados por Weber et al. (2003), com as cultivares Perolera $(0,098-0,124 \mathrm{~g})$ e Primavera $(0,231-0,239 \mathrm{~g})$.

Os valores médios de área foliar, altura e massa seca da parte aérea das mudas do abacaxizeiro cv. Gold são sempre menores na bandeja de isopor do que nos outros recipientes, provavelmente, devido ao seu menor volume, que disponibiliza menos substrato e nutrientes para o sistema radicular. Observação semelhante foi feita por Araújo et al. (2006), em avaliação aos 60 dias após semeadura, para altura das plantas, número de folhas e diâmetro do caule de mudas de mamoeiro cultivadas em diferentes recipientes e sob viveiro telado.

\section{CONCLUSÕES}

Nas condições em que foi realizado este experimento pode-se concluir que:

Todos os adubos foliares, em todos os recipientes utilizados, proporcionaram maior crescimento em área foliar, altura e massa seca da parte aérea às mudas do abacaxizeiro cv. Gold, exceto os adubos foliares T5 e T7, para massa seca da parte aérea no recipiente bandeja de isopor;

Os adubos foliares utilizados não aumentaram a massa seca do sistema radicular;

O recipiente bandeja de isopor apresentou as menores médias de área foliar, altura e massa seca da parte aérea das mudas do abacaxizeiro cv. Gold, em todos os níveis de adubo foliar utilizados;

Os recipientes tubete pequeno e tubete grande não diferiram entre si, em todos os níveis de adubo foliar, exceto para o adubo foliar $\mathrm{T} 7$ para massa seca da parte aérea e no adubo foliar T1, para massa seca da raiz e altura de planta.

\section{AGRADECIMENTOS}

Ao Incaper e ao Laboratório Biomudas pela cessão das mudas do abacaxizeiro cv. Gold, ao CCA-UES, pelo apoio em infra-estrutura.

\section{REFERÊNCIAS BIBLIOGRÁFICAS}

ARAÚJO, J. R. G.; ARAÚJO JÚNIOR, M. M.; MENEZES, R. H. N.; MARTINS, M. R.; LEMOS, R. N. S.; CERQUEIRA, M. C. M. Efeito de recipiente e ambiente de cultivo sobre o desenvolvimento de mudas de mamoeiro cv. Sunrise solo. Revista Brasileira de Fruticultura, Jaboticabal, v. 28, n. 3, p. 526-529, dez. 2006.

BENINCASA, M. M. P. Análise de crescimento de plantas: noções básicas. 2. ed. Jaboticabal: FUNEP, 2003. 41 p.
COELHO, R. I. Clonagem do abacaxizeiro a partir de coroas e secções de caule tratados com reguladores de crescimento e fertilizantes químicos. 2005. 114 f. Tese (Doutorado em Produção Vegetal) - Centro de Ciências e Tecnologias da Universidade Estadual do Norte Fluminense Darcy Ribeiro, Campos dos Goytacazes, 2005.

MARTINS, C. P.; NÓBREGA, F. S.; ALOUFFA, M. A. I.; BARROSO, A. V.; LOPES, D. B.; MACÊDO, C. E. C. Cultivo hidropônico de plântulas de abacaxizeiro (Ananas comosus (L) Merril) obtidas in vitro. In: CONGRESSO BRASILEIRO DE FRUTICULTURA, 17., 2002, Belém. Anais eletrônicos... 2002. Disponível em: <http://www.ufpel.tche.br./sbfruti/ anais_xvii_cbf/fitotecnia/392.htm.>. Acesso em: 10 mar. 2006.

MELLO, M. R. F.; MARIANO, R. L. R.; MENEZES, M.; CÂMARA, T. R.; ASSIS, A. M. P. Seleção de bactérias e métodos de bacterização para promoção de crescimento em mudas de abacaxizeiro micropropagadas. Summa Phytpathologica, Jaguariuna, v. 28, p. 222-228, 2002.

MOREIRA, M. A. Produção e aclimatização de mudas micropropagadas de abacaxizeiro: Ananas comosus (L) Merrill cv. Pérola. 2001. 81 f. Tese (Doutorado em Fitotecnia) Universidade Federal de Lavras, Lavras, 2001.

MOREIRA, M. A.; CARVALHO, J. G.; PASQUAL, M.; FRÁGUAS, C. B.; SILVA, A. B. Efeito de substratos na aclimatização de mudas micropropagadas de abacaxizeiro cv. Pérola. Ciência e Agrotecnologia, Lavras, v. 30, n. 5, p. 875-879, set./out. 2006.

REINHARDT, D. H. R. C. Manejo e produção de mudas de abacaxi. Informe Agropecuário, Belo Horizonte, v. 19, n. 195, p. 13-19, 1998.

REINHARDT, D. H. R. C.; CUNHA, G. A. P. Métodos de propagação. In: CUNHA, G. A. P.; CABRAL, J. R. S.; SOUZA, L. F. S. (Orgs.). O abacaxizeiro: cultivo, agroindústria e economia. Brasília, DF: Embrapa, 1999. p. 105-138.

SIEBENEICHLER, S. C.; MONNERAT, P. H.; CARVALHO, A. J. C.; SILVA, J. A.; MARTINS, A. O. Mobilidade do boro em plantas de abacaxi. Revista Brasileira de Fruticultura, Jaboticabal, v. 27, n. 2, p. 292-294, ago. 2005.

SIEBENEICHLER, S. C.; MONNERAT, P. H.; CARVALHO, A. J. C.; VIEIRA, A.; SILVA, J. A. Efeito do boro foliar na cultura do abacaxi no noroeste fluminense. In: CONGRESSO BRASILEIRO DE FRUTICULTURA, 17., 2002, Belém. Anais eletrônicos... 2002. Disponível em: <http.//www.ufpel.tche.br/ sbfruti/anais_xvii_cbf/climassolos.nutricao/249.htm>. Acesso em: 23 mar. 2006. 
SILVA, A. B.; PASQUAL, M.; MOREIRA, M. A.; MACIEL, A. L. R.; ALVES, J. M. C.; PEREIRA, A. B. Aclimatação de brotações de abacaxi (Ananas comosus (L.) produzidas in vitro: ação de agromix $^{\circledR}$, húmus e $\operatorname{Kelpak}^{\circledR}$. Revista da Universidade de Alfenas, Alfenas, n. 4, p. 107-110, 1998.

SOUZA JÚNIOR, E. E.; BARBOZA, S. B. S. C.; SOUZA, L. A. C. Efeitos de substratos e recipientes na aclimatação de plântulas de abacaxizeiro [Ananas comosus (L.) Merril] cv. Pérola. Pesquisa Agropecuária Tropical, Goiânia, v. 31, n. 2, p. 147-151, 2001.
SOUZA, L. F. S. Correção de acidez e adubação. In: CUNHA, G. A. P.; CABRAL, J. R. S.; SOUZA, L. F. S. (Orgs.). O abacaxizeiro: cultivo, agroindústria e economia. Brasília, DF: Embrapa, 1999. p. 169-202.

WEBER, O. B.; CORREIA, D.; ROCHA, M. W.; ALVES, G. C.; OLIVEIRA, E. M.; SÁ, E. G. Resposta de plantas micropropagadas de abacaxizeiro à inoculação de bactérias diazotróficas em casa de vegetação. Pesquisa Agropecuária Brasileira, Brasília, v. 38, n. 12, p. 14191426, dez. 2003. 